\title{
Changing Pattern of Prescribing of Drugs in Patients of Hypertension and Type-2 Diabetes Mellitus in Rural Healthcare Settings in North India
}

\author{
Zahida Parveen ${ }^{1}$, Shahid Hussain ${ }^{2 *}$ \\ ${ }^{1}$ Medical Officer, J\&K Health Services, \\ ${ }^{2}$ Senior Resident, Department of Community Medicine, Govt. Medical College, Jammu, J\&K, India.
}

\begin{abstract}
Introduction: Drug utilization studies are powerful exploratory tool to ascertain the role of drugs. They create a sound sociomedical and health economic basis for health care decision making.

Objectives: The study was aimed to find out the changing pattern of prescribing the antihypertensive and anti-diabetic drugs in patients suffering from Hypertension and Diabetes.

Methods: This prospective, observational study was done on 50 patients of Hypertension and Diabetes. Each patient was followed up over a period of 3 months and analysis of prescription was done.

Results: An average of 2.42 drugs prescribes at first, 2.76 at $1^{\text {st }}$ follow up and an average of 3.23 drugs at $2^{\text {nd }}$ follow up. Percentage of generic drugs was $35.5 \%$ at first visit, $30.7 \%$ at 1 st follow up and $30 \%$ at $2^{\text {nd }}$ follow up. Antibiotics were prescribed in $4.1 \%$ prescriptions at $1^{\text {st }}$ visit, $2.3 \%$ at 1 st follow up and $1.3 \%$ at $2^{\text {nd }}$ follow up. ACE inhibitors were most frequently prescribed and among combination $\mathrm{CCB}$ and $\beta$ blockers were most frequently prescribed. Among antidiabetics Metformin was most frequently prescribed. Most common modification to therapy was Add on. Switching of drugs to another therapeutic class was seen only in patients of Hypertension.
\end{abstract}

\section{INTRODUCTION}

Drug utilization research is an essential part of pharmacoepidemiology as it describes the extent, nature and determinants of drugs being used to treat particular conditions. ${ }^{1}$ Drug use is complex process and a large number of socio-cultural factors contribute to the way drugs are used.Type-2 Diabetes Mellitus is currently an epidemic, prevalence of which for all age groups across the world was $2.8 \%$ in 2000 and is estimated to be $4.4 \%$ in 2030. Pharmacotherapy of Type-2 Diabetes Mellitus includes oral hypoglycaemic and sometimes Insulin also. Many newer international and national guidelines are available which provide evidence based recommendations for treatment. ${ }^{2.3}$

Hypertension is another major chronic disease resulting in high morbidity and mortality in the world population. In 2000 Hypertension was estimated to affect almost one billion patients worldwide and prevalence is predicted to increase by $60 \%$ by 2025.4 Treatment of Hypertension and Diabetes Mellitus is constantly evolving and the resultant changes in drug use may have medical, social and economic implications both for individual patients and for populations. Therefore, the present study was conducted to analyse the prescribing patterns of anti-hypertension and anti-diabetic agents in view of reported disparity between recommended and actual practices for pharmacological management.
Conclusions: This study showed ACE inhibitors and ARB's as most commonly prescribed antihypertensive drugs. Combination of metformin and Glimipride was commonest among antidiabetic drugs and most common modification seen was Add on.

Key words: Add on, Chronic Diseases, Follow Up, Monotherapy, Pharmacotherapy, Switched.

*Correspondence to:

Dr Shahid Hussain, Senior Resident, Department of Community Medicine, Govt. Medical College Jammu J\&K, India.

Email: majorshahid786@gmail.com

Article History:

Received: 02-05-2016, Revised: 12-05-2016, Accepted: 31-05-2016

\begin{tabular}{|l|r|}
\hline \multicolumn{2}{|c|}{ Access this article online } \\
\hline $\begin{array}{l}\text { Website: } \\
\text { www.jmmrp.com }\end{array}$ & Quick Response code \\
\hline DOI: & \\
10.21276/ijmrp.2016.2.3.039 & \\
\hline
\end{tabular}

\section{AIMS AND OBJECTIVES}

Assessment of changing pattern of prescription of antihypertensive and anti-diabetic drugs in patients suffering from Hypertension and Diabetes.

\section{MATERIALS AND METHODS}

The present prospective observational study was conducted in Out-patient department of Community Health Centre RS Pura, situated in rural area of North India for a period of three months after getting approval from the Institutional Ethics Committee. 50 patients having chronic diseases like Hypertension and Diabetes who agreed to be followed up twice within a period of 3 months were enrolled. Firstly pattern of use of anti-hypertensives and antidiabetic drugs was done as per WHO guidelines on how to investigate drug use in health facilities ${ }^{4}$ using some prescription and patient care indicators.

Subsequently initial treatment and subsequent modification to therapy were documented. Initial treatment regimen was defined as regimen which patients were already taking at the time of enrollment. Any change to the initial drug class was considered as modification to therapy. A patient's status was classified as switched if a different therapeutic class was prescribed. Patients were classified as add on if patient is taking initial agent and 
simultaneously prescribed with an additional agent. Patients were classified as discontinued if they had stopped taking drug for at least 30 days. Data thus collected was tabulated and analyzed using Microsoft Office Excel.

Fig 1: Age and Sex Characteristics of patients with chronic diseases

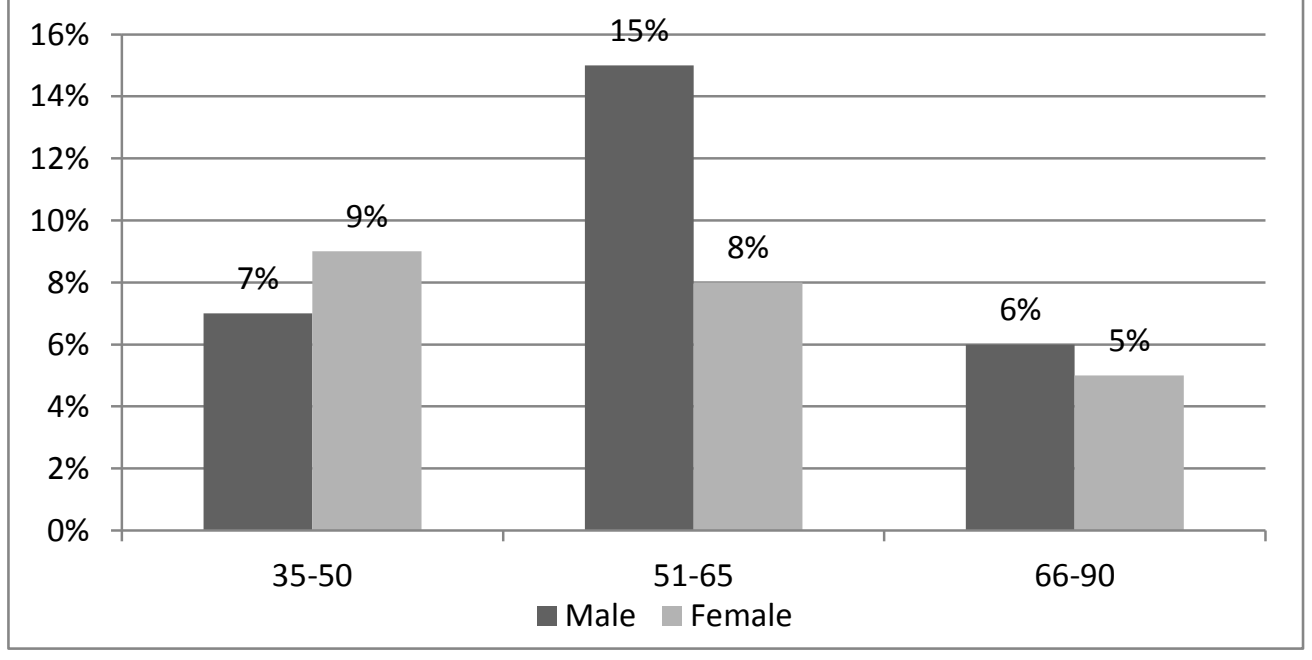

Table no 1: Analysis of prescribing indicators of study population with chronic diseases

\begin{tabular}{lccc}
\hline Prescribing indicators & First visit & $\begin{array}{c}\text { Follow up } \\
\text { visit 1 }\end{array}$ & $\begin{array}{c}\text { Follow up } \\
\text { visit 2 }\end{array}$ \\
\hline Total number of prescriptions analyzed & 50 & 48 & 45 \\
Total number of drugs prescribed & 121 & 130 & 145 \\
Average number of drugs per prescription & 2.42 & 2.76 & 3.23 \\
\%age of drugs prescribed by generic name & 35.5 & 30.7 & 30 \\
\%age of prescriptions with an antibiotic & 4.1 & 2.3 & 1.3 \\
\%age of prescriptions with an injection & 1.6 & 0.7 & 1.3 \\
\%age of drugs prescribed from EDL & 53.7 & 50.76 & 50.2 \\
\hline
\end{tabular}

Table no 2: Patient care indicators

\begin{tabular}{llll}
\hline Patient care indicators & First visit & Follow-up visit 1 & Follow-up visit 2 \\
\hline Average consultation time & $3.4 \mathrm{~min}$ & $3.32 \mathrm{~min}$ & $3.4 \mathrm{~min}$ \\
\%age knowledge of correct dosage & $94 \%$ & $95.7 \%$ & $95.5 \%$ \\
\hline
\end{tabular}

Table 3: Distribution of patients prescribed Anti-Hypertensive drugs according to class.

\begin{tabular}{ccccccc}
\hline Drug class & \multicolumn{2}{c}{ First visit } & \multicolumn{2}{c}{ Follow up visit 1 } & \multicolumn{2}{c}{ Follow up visit 2 } \\
\cline { 2 - 7 } Calcium channel blockers & Frequency & \%age & Frequency & $\%$ age & Frequency & \%age \\
$\beta$ blockers & 03 & 12 & 03 & 13 & 02 & 8.33 \\
Diuretics & 04 & 16 & 03 & 13 & 02 & 8.33 \\
ACE inhibitors & Nil & Nil & Nil & Nil & 01 & 4.16 \\
AR blockers & 08 & 32 & 06 & 26 & 03 & 12.5 \\
Calcium channel blockers + $\beta$ blockers & 05 & 20 & 06 & 26 & 09 & 37.5 \\
Calcium channel blockers + AR blockers & 03 & 12 & 03 & 13 & 05 & 20.83 \\
Diuretics + ARB & 01 & 4 & 01 & 4.3 & 01 & 4.16 \\
\hline
\end{tabular}

Table 4: Distribution of patients prescribed anti-hypertensive monotherapy and combination therapy.

\begin{tabular}{llll}
\hline Drug therapy & First visit (\%) & Follow up visit 1 (\%) & Follow up visit 2 (\%) \\
\hline Monotherapy & 80 & 78 & 70.82 \\
Combination & 20 & 21.6 & 29.15 \\
\hline
\end{tabular}

Table 5: Distribution of patients prescribed Anti-Diabetic drugs according to class.

\begin{tabular}{lllllll}
\hline Drug class & First visit & & \multicolumn{2}{l}{ Follow up visit 1 } & \multicolumn{2}{l}{ Follow up visit 2 } \\
\cline { 2 - 7 } & Frequency & $\%$ age & Frequency & $\%$ age & Frequency & $\% a g e$ \\
Metformin & 8 & $32 \%$ & 8 & $30.7 \%$ & 4 & $16 \%$ \\
Insulin Mixtard & 1 & $4 \%$ & 1 & $3.8 \%$ & 1 & $4 \%$ \\
Insulin Glargine & - & - & - & - & 1 & $4 \%$ \\
Metformin +glimipride & 12 & $48 \%$ & 13 & $50 \%$ & 15 & $60 \%$ \\
Vildagliptin +metformin & 4 & $16 \%$ & 4 & $15.38 \%$ & 4 & $16 \%$ \\
\hline
\end{tabular}


Zahida Parveen \& Shahid Hussain. Changing Prescription Pattern for HTN and DM

Table no 6: Modification of therapy

\begin{tabular}{lllll}
\hline Modification & \multicolumn{2}{c}{ Anti-Hypertensive drugs } & \multicolumn{2}{c}{ Anti-Diabetic drugs } \\
\cline { 2 - 5 } & Follow up & Follow up & Follow up & Follow up \\
& visit 1 & visit 2 & visit 1 & visit 2 \\
Addition & 01 & 04 & 02 & 07 \\
Switch & 01 & 02 & - & - \\
Discontinue & - & - & - & - \\
\hline
\end{tabular}

\section{RESULTS}

In this cross-sectional study, a cohort of 50 patients of Hypertension and Diabetes Mellitus were recruited. The patients studied were in age group of 35 to 90 years with maximum patients in age group of $51-65$ years with mean age $57.95 \% \pm 4.27$ both in males and females as shown in Fig 1.

Out of 50 prescriptions at first visit, total numbers of drugs prescribed were 121 which make an average of 2.42 drugs per prescription. Percentages of drugs by generic name were $35.5 \%$. Antibiotics were prescribed in $4.1 \%$ prescriptions and injections were $1.6 \%$ per prescription. A total of $53.7 \%$ drugs were prescribed from essential drug list.

At first follow-up after one month, two patients were lost to followup and out of 48 prescriptions; total numbers of drugs were 130 with an average number of drugs 2.76 per prescription. Drugs by generic name were $30.7 \%$. Antibiotics were prescribed in $2.3 \%$ prescriptions and $0.7 \%$ per prescription was injections. Half of the drugs $(50.76 \%)$ were from essential drug list.

At second follow-up three more patients were lost to follow-up. So in 45 prescriptions, total number of drugs prescribed was 145 with an average of 3.23 per prescription indicating an increasing trend. $30 \%$ drugs were prescribed by generic name and $50.2 \%$ drugs were from essential drug list. $1.3 \%$ prescriptions contained an antibiotic as shown.

Average consultation time for first visit and follow-up 2 was 3.4 minutes each and 3.32 minutes for follow-up 1. Percentage knowledge of correct dosage was also almost equal for all three visits as shown in table 2 .

Among antihypertensive drugs, ACE inhibitors were most frequently prescribed followed by AR blockers and $\beta$ blockers at first visit but follow-up visits showed an increasing trend of prescribing AR blockers. Least prescribed drug class was diuretics. Among combinations, calcium channel blockers $+\beta$ blockers was most frequently used in all three visits followed by combination of diuretics + AR blockers as shown in table 3 .

In hypertensive patients, majority i.e. $80 \%$ were treated with monotherapy in first visit, $78 \%$ in follow up- 1 and $70.82 \%$ in follow up- 2. Combination therapy was used in nearly equal number of patients at first visit and follow up- $1(20 \%$ and $21.6 \%)$ but use of combination therapy increased in follow up- $2(29.15 \%)$ as shown in table 4.

Among anti-diabetic drugs, Metformin was most frequently prescribed in all three visits. In combination therapy, Metformin +Glimipride was most frequently prescribed followed by combination of Vildagliptin+metformin as shown in table 5.

After two follow-up visits at one month and three months, majority of study subjects continued with initial treatment. Most common modification to therapy was Add-on. Additions of three drugs were noted at follow-up visit 1and eleven drugs at follow-up visit 2. A total of three drugs were switched to another therapeutic class only in patients of hypertension as shown in table 6 .

\section{DISCUSSION}

Prescription pattern in chronic diseases like hypertension and diabetes was investigated so as to gain insight into how these disorders are managed particularly with regards to prescription behaviour of physicians. The idea was to identify major points for future intervention in the management of these disorders as well as ways to avoid possible complications.

The epidemiological distribution with regards to age and occurrence of diabetes mellitus and hypertension in studied population showed a similar pattern as reported by other workers. ${ }^{5,6}$ This gives us enough liberty to analyze our finding within the larger context despite the sample being small and possibly not representative. Therefore, the findings emerging out of longitudinal follow up of small sample of this size ends up usefully addressing the prescription behaviour in chronic disease management at secondary care level.

A closer look of the available data about average number of drugs at baseline and three months shows a consistent pattern i.e. an increasing trend across different settings. It is possible to explain the pattern being due to the concomitant presence of co-morbid conditions and complications, so the patients may require more drugs than as stated by WHO. In such cases polypharmacy can be acceptable. It is of interest though that generic drugs and drugs from essential drug list were observed to be used more frequently in these patients than other investigators. ${ }^{5}$ Also the prescriptions related to antibiotic use was lower, possibly referring to lower levels of complications due to infectious agents or a better control of diabetes or both. This finding however needs to be seen with caution as the duration of follow up was too short to document the actual state of affairs. ${ }^{7}$

Similarly the lower use of injections observed in the study as opposed to a higher use reported by others ${ }^{8}$ could simply be attributable to predominance of Type 2 diabetes in the sample studied, a condition in which treatment of choice is oral hypoglycaemics. Over a last couple of decades, there has been exponential increase in the use of antihypertensive drugs like ACE inhibitors, ARBs and CCBs particularly after $1990^{\prime} \mathrm{s}^{9}$ as is evident from present study. The situation was different before 90's as diuretics and Beta Blockers were the most commonly prescribed drugs. As per JNC VII, diuretics are being favoured in the management of hypertension as they are known to enhance the antihypertensive efficacy of multidrug regimen to achieve blood pressure control. ${ }^{10}$ Diuretic as monotherapy is very infrequently prescribed but its use was restricted to its combination with CCBs. Still others have reported more frequent use of ACE inhibitors and $\mathrm{CCBs}^{11,12}$ as also reported in present study. Hypertension is better controlled by combination therapy but present study showed monotherapy to be more commonly prescribed than combinations. Greater use of combination of Metformin and Glimipride as compared to mono therapy was observed in our sample which indicates rational management of diabetes and is in consistence 
with results reported by other researchers. ${ }^{13}$ This combination is most desirable and having a rational basis of use i.e. both of these drugs act through different mechanisms, one is Insulin sensitizer and other acts as Insulin secretagogue. ${ }^{14}$ Less frequent Metformin monotherapy and insulin use and combination of Vildagliptin and Metformin could be rationally explained by the nature of diabetics studied in different settings. ${ }^{5,7}$

Lifelong treatment is usually necessary for persons diagnosed with chronic diseases like Hypertension and Diabetes. Many factors contribute to addition or switching of drugs. Lack of persistence, addition or switching is likely signal for ineffective treatment, intolerance or adverse drug reactions. In current study majority of patients continued with initial treatment. Thus persistence with initial drug therapy may be explained by better disease control and favourable tolerability profile of the drug.

In our study, addition of another drug from different class was most common modification like most other investigators ${ }^{15,16}$ (Bourgault C et al., 2001 and Vipul P et al., 2003). Switching from one therapeutic class to another is seen in some hypertensive patients as also reported by other ${ }^{17}$ (Martie $C$ et al 2013). Two most important reasons which contribute to addition or switching of drugs are inadequate blood pressure control and adverse effects (Dusing R et al., 1998). ${ }^{18}$

\section{LIMITATIONS}

Number of prescriptions studied for chronic diseases for Hypertension and Diabetes was low with short follow up time. Hence similar studies covering larger number of patients with longer follow up period are needed to confirm our findings.

\section{CONCLUSION}

The information gathered from the study should be a pointer to the trends in prescribing drugs and could serve a framework upon which further studies can be launched to investigate the scope for improvement. Educational intervention and short problem based training course and workshops are needed to improve prescription behaviour of doctors. Also adoption of international standard and locally comfortable guidelines on rational use of drugs can help to resolve such problems.

\section{REFERENCES}

1. Sjoqvist F, Birkett D. Drug utilization. In: Bramley DW, editor. Introduction to Drug Utilization Research (WHO Booklet). New York: WHO Office of Publication; 2003: 76-84.

2. Bergers JS, Bailey JV, Klazinga NS, Van Der By AK, Grall R. Comparative analysis of recommendations and evidence in Diabetes guidelines from 13 countries. Diabetes Care. 2002;25(2):1933-1939.

3. WHO. How to Investigate Drug Use in Health Facilities: Selected Drug Use Indicators. World Health Organization. 1993. http://apps.who.int/medicinedocs/en/d/Js2289e/ Last assessed on 16 Mar 2016.

4. Kearney PM, Whelton M, Reynolds K, Muntner P, Whelton PK, He J. Global burden of hypertension: analysis of worldwide data. Lancet. 2005;365:217-23.

5. Kaur S, Gupta S, Kumar D, Lal M, Gilani Z. Prescribing Pattern of Antihypertensive Drugs in a Tertiary Care Hospital in Jammu- A Descriptive study. JK- Practitioner. 2012;17(4):38-41.

6. Sharma P, Sharma N, Parakh R, Sharma N, Gautam B, Motiwale S. Screening of Prescriptions in Patients of Type-2 Diabetes Mellitus in a Tertiary Care Teaching Hospital. International journal of Pharmaceutical research and bio-science. 2014;3(1):401-409.

7. Adibe MO. Outpatient Utilization of Anti-diabetic Drugs in the South Eastern Nigeria. Int.j.drug dev \& res. 2009;1(1):27-36.

8. Batainah Z, Khasawneh NF, Kofahi S, Moqasqas MK. Assessment of Drug Use by Diabetics-Experience at JUST Priาmary Health Care Center in Irbid, Jordan. Jordan journal of applied science "Natural Sciences Series". 2013;11(1):45-60.

9. Jhaj R, Goel NK, Gautam CS, Hota D, Sangeeta B, Sood A, Sachdev A. Prescribing Patterns and Cost of Antihypertensive Drugs in an Internal Clinic; Indian Heart j. 2001;53(3):323-327.

10. Dahlof B, Sever PS, Poulter NR, Wedel H, Beevers DG, Caulfield $M$ et al. Prevention of cardiovascular events with an anti-hypertensive regimen of amlodipine adding perindopril as required versus atenolol adding bendroflumethiazide as required in the Anglo-Scandinavian cardiac Outcomes Trial- Blood Pressure Lowering Arm (ASCOTBPLA). A Multicentre Randomised Controlled Trial. Lancet. 2005;366:895-906.

11. Arief M, Harika B, Satyanarayana B, Pasha SW, Paladugu ND, Pasha SI. Evaluation of Prescribing Pattern of Antihypertensive Drugs in a Tertiary Care Hospital. Acta Chim. Pharm. Indica. 2013 ;3(2):172181.

12. Sivasakthi R, Thomas S, Sivakumar KK, Kartikeyan J, Sarvana KN. Assessment of Anti-Hypertensive Prescribing Pattern and Patient Counselling in An Urban Population. Der Pharmacia Lettre. 2010;2(4):156-163.

13. Acharya KG, Shah KN, Solanki ND, Rana DA. Evaluation of Antidiabetic Prescriptions, Cost and Adherence to Treatment Guidelines: A Prospective, Cross-Sectional Study at a Tertiary Care Teaching Hospital. Journal of Basic and Clinical Pharmacy. 2013;4(4):82-87.

14. Sivasankari V, Manivannan E, Priyadarsini SP. Drug Utilization Pattern of Anti-Diabetic Drugs in a Rural Area of Tamilnadu, South India - a Prospective, Observational Study. Int J Pharm Bio Sci. 2013;4(1):514-519.

15. Bourgault C, Rainville B, Suissa S. Antihypertensive Drug Therapy in Saskatchewan. Arch Intern Med. 2001;161:1873-1879.

16. Vipul P Chaudhari, Berna Ganguly. Changing pattern of prescribing antidiabetic agents in patients suffering from diabetes mellitus. Int J Basic Clin Pharmacol. 2013; 2(1): 47-50.

17. Wong MCS, Tam WWS, Cheung CSK, Tong ELH, Sek ELH, et al. Initial Antihypertensive Prescription and Switching: a 5 year cohort study from 250,851 patients. PLoS One. 2013,8(1): e53625.

18. $R$ Dusing, B Weisser, $T$ Mengden, $H$ Vetter. Changes in Antihypertensive therapy. The role of adverse effects and compliance. Blood pressure. 1998;7(5-6):313-315.

\section{Source of Support: Nil. Conflict of Interest: None Declared.}

Copyright: (c) the author(s) and publisher. IJMRP is an official publication of Ibn Sina Academy of Medieval Medicine \& Sciences, registered in 2001 under Indian Trusts Act, 1882.

This is an open access article distributed under the terms of the Creative Commons Attribution Non-commercial License, which permits unrestricted non-commercial use, distribution, and reproduction in any medium, provided the original work is properly cited.

Cite this article as: Zahida Parveen, Shahid Hussain. Changing Pattern of Prescribing of Drugs in Patients of Hypertension and Type2 Diabetes Mellitus in Rural Healthcare Settings in North India. Int J Med Res Prof. 2016; 2(3):179-82. 